\title{
Entrevistas a estudiantes
}

\section{Alumna, $4^{\circ}$ de la ESO, 16 años, IES Fray Luis de León, Provincia de Cuenca}

Indica cuántos miembros conviviendo en casa en este momento de confinamiento, edad de cada miembro, nivel educativo de cada miembro y a qué se dedica, con especial atención a si se está en casa o tiene un empleo que le obliga a salir en este momento.

4 miembros:

- 47 años, licenciado, procurador de los tribunales

- 43 años, licenciada, gerente en librería

- 16 años, $4^{\circ}$ ESO, estudiante

- 14 años, $3^{\circ} \mathrm{ESO}$, estudiante

Explica brevemente cómo se distribuyen las labores del hogar entre sus miembros durante el confinamiento: tareas que se han realizado en el hogar durante la última semana y duración (aproximada) de cada tarea, así como miembro del hogar que la ha realizado. Señala también si ha cambiado esa distribución en relación a antes del confinamiento.

El 90\% de las tareas domésticas las hace mamá, incluso ha aumentado su trabajo en casa durante el confinamiento.

Yo dedico unos 15 minutos diarios en ordenar la habitación, ayudo a poner y quitar la mesa, hacer mi cama y algunos días friego.

Realización del trabajo escolar:

¿De qué medios tecnológicos se dispone en casa (un ordenador, varios ordenadores, una tablet, un móvil inteligente, ninguno de éstos) para hacer el seguimiento virtual de los deberes?

Disponemos de un portátil, una tablet y cuatro móviles (uno por miembro de la familia).

¿Cómo es la conexión a internet (tipo de conexión -4G, Fibra, Rural...-y velocidad)? Fibra con alta velocidad. 
¿Qué se está haciendo desde el centro educativo? ¿Por qué vía llegan los deberes? ¿Cómo es la interacción con el tutor/a y con el resto del profesorado? ¿Cómo es la interacción con el padre o la madre con el IES? ¿Cómo se corrigen los ejercicios? ¿Cómo se está planteando la evaluación del $2^{\circ}$ trimestre?

Algunos profesores dan clases por plataformas como Skype, Zoom... Suelen mandar deberes cada semana y otros ni siquiera se ponen en contacto con nosotros.

Los deberes llegan por papas, classroom, y por correo.

Solemos estar en contacto semanalmente o diariamente con el profesorado.

La interacción del IES con mis padres hasta la fecha, no se ha producido.

Algunos profesores envían las respuestas para que podamos corregir los ejercicios, otros utilizan el Skype y el Zoom para corregirlos y así poder preguntar dudas; y en otras asignaturas no los hemos corregido.

¿Qué horario ocupa a lo largo del día? ¿Qué actividades se realizan, cómo es esta rutina?

Toda la mañana y a veces por la tarde.

Suelo realizar clases por Zoom y Skype y hago los deberes que se corresponden a cada día de la semana.

Percepción de si esta forma de seguir el curso está teniendo algún impacto en su aprendizaje y en qué sentido.

Está teniendo un impacto negativo. No aprendemos casi nada nuevo y lo único que hacen es mandarnos cantidades exageradas de deberes.

Dificultades que se encuentra a la hora de hacer realizar los deberes de esta manera. A veces el «Papás 2.0» se colapsa y es imposible enviar los ejercicios y otras veces no llega bien la conexión y no podemos acceder a internet.

\section{Principales conclusiones que extrae de esta experiencia educativa.}

Bajo mi punto de vista, esta experiencia es extraña para todos e intentamos llevarla con la mayor calma posible aunque no es fácil y aunque nos llevemos alguna parte positiva de todo esto, sinceramente pienso que va a ser un trimestre perdido.

¿Cree que está teniendo algún impacto en términos de igualdad o desigualdad para el alumnado? y en caso afirmativo, ¿̇en qué sentido?

De desigualdad, porque hay alumnos que no disponen de los medios necesarios para realizar las tareas y no todos tienen acceso a internet.

Balance de esta experiencia de confinamiento y de teletrabajo educativo:

Principales debilidades y dificultades, situaciones de estrés, de conflicto con las hijas/ os, con la pareja, con las personas dependientes.

El hecho de estar encerrada me hace sentir agobiada o estresada con la situación y también, algunas veces, con mis padres. 


\section{¿Algún aspecto positivo? ¿̇alguna contribución? ¿algo que se extraiga como una ven- taja en medio de esta situación compleja? ¿alguna reflexión en términos de crecimien- to personal?}

Aumentar los conocimientos en las tecnologías, pasar más tiempo con la familia y aprender a ser más fuertes a nivel emocional.

Y en términos emocionales, afectivos y personales, ¿̇cómo se está viviendo? ¿̇cómo se está gestionando?

Por mi parte no está siendo demasiado duro, aunque siempre vienen bajones y situaciones de estrés.

\section{Aprendizaje para el futuro.}

Prefiero la enseñanza tradicional ya que no me gusta nada este tipo de enseñanza porque tanto los profesores como los alumnos estamos mucho más relajados.

Valoración sobre las consecuencias y el impacto educativo y social de esta crisis a corto y medio plazo, una vez que se supere la situación.

Sobre el tema de educación hemos dejado de aprender muchos contenidos.

Socialmente pienso que cuando acabe el confinamiento haremos más uso de los espacios abiertos y limitaremos el contacto físico.

Alguna consideración o comentario final que consideres adecuado o quieras hacer. Quiero hacer un comentario final sobre mis sentimientos. Estando en casa no me siento muy agobiada ya que me gusta pasar tiempo aquí, pero sí estoy triste la mayoría de los días porque echo de menos a familiares y amigos y espero que todo esto termine pronto y podamos volver a la normalidad poco a poco. 


\section{Alumna, 17 años, $1^{\circ}$ de Bachillerato, IES Fray Luis de León, Provincia de Cuenca}

Indica cuántos miembros conviviendo en casa en este momento de confinamiento, edad de cada miembro, nivel educativo de cada miembro y a qué se dedica, con especial atención a si se está en casa o tiene un empleo que le obliga a salir en este momento.

Somos tres miembros: mi madre y mi padre con 45 años y yo con 17.

Mi madre tiene estudios universitarios (actualmente desempleada) y mi padre educación básica. Él tiene una empresa de construcción, por lo que ha respetado las distintas indicaciones propias del estado de alarma.

Explica brevemente cómo se distribuyen las labores del hogar entre sus miembros durante el confinamiento: tareas que se han realizado en el hogar durante la última semana y duración (aproximada) de cada tarea, así como miembro del hogar que la ha realizado. Señala también si ha cambiado esa distribución en relación a antes del confinamiento.

Durante el confinamiento las tareas se han repartido más equitativamente. Si bien es cierto que el «mundo de las lavadoras» ha recaído mas sobre mi madre, y pequeñas reformas o tareas más complicadas sobre mi padre.

La que más se «escaquea», la verdad, soy yo.

Realización del trabajo escolar:

¿De qué medios tecnológicos se dispone en casa (un ordenador, varios ordenadores, una tablet, un móvil inteligente, ninguno de éstos) para hacer el seguimiento virtual de los deberes?

Dos ordenadores y varios móviles de última generación. El seguimiento virtual de los deberes se hace con el uso de mi ordenador.

¿Cómo es la conexión a internet (tipo de conexión -4G, Fibra, Rural...- y velocidad)? Muy mala, porque la instalación no permite una conexión óptima. Se agradecen los GB que movistar nos ha regalado con motivo de la crisis del COVID-19.

¿Qué se está haciendo desde el centro educativo? ¿Por qué vía llegan los deberes? ¿Cómo es la interacción con el tutor/a y con el resto del profesorado? ¿Cómo es la interacción con el padre o la madre con el IES? ¿Cómo se corrigen los ejercicios? ¿Cómo se está planteando la evaluación del $2^{\circ}$ trimestre?

Las tareas nos las hacen llegar o bien por Gmail, o por la plataforma educativa de Papás 2.0. Nos avisan con tiempo dejándonos varios días para entregar las tareas.

Algunos de los profesores dan clase por Skype, otros se graban videos explicando y los suben a un blog, y otros no hacen nada, la verdad.

$\mathrm{Al}$ tener 17, tengo autonomía y mis padres pues no tienen por qué ponerse conmigo.

En cuanto a la forma de evaluar aún no saben nada, pero nos han dicho que todo lo que estamos haciendo durante la cuarentena puntuará. 
Apuntar también, que en el conservatorio, a nivel de grado profesional, todas y cada una de las clases se están dando por Skype, hay mucha implicación por parte del profesorado, y sinceramente no he notado que hayamos bajado el ritmo, lo estamos llevando todo al día.

\section{¿Qué horario ocupa a lo largo del día? ¿Qué actividades se realizan, cómo es esta rutina?}

Intento llevar al día los ejercicios y las clases online, para no acumular mucho trabajo, aunque a veces esto es un poco complicado, porque el confinamiento es muy duro, y me refugio en Netflix y en la comida [Risas]. A veces también hago deporte, pinto cuadros... Sinceramente me faltan horas. En el fondo esta vida me gusta.

\section{Percepción de si esta forma de seguir el curso está teniendo algún impacto en su} aprendizaje y en qué sentido.

Yo no me entero de nada (excepto las asignaturas que sí dan clases, como ya he nombrado antes), en muchas materias nos mandan copiar sin conocer realmente el objetivo de dicha tarea, y creo que no es el método más adecuado. Además llevan muchísima velocidad, y están dando los temas muy rápido y sin detenerse lo que en condiciones normales se detendrían.

\section{Dificultades que se encuentra a la hora de hacer realizar los deberes de esta manera.}

Al estar todo el mundo conectado a internet, la velocidad de este se ha reducido, complicando bastante la resolución rápida y eficaz de dudas que nos puedan surgir mientras realizamos los ejercicios.

\section{Principales conclusiones que extrae de esta experiencia educativa.}

Por un lado me gusta, porque puedo administrar mi tiempo como quiero, ver la clase online o hacer los ejercicios sin la necesidad de madrugar. Pero la parte que más me incumbe que es la de aprender y formarme de la mejor manera posible para el terrible año que me espera el que viene, en segundo de bachiller, creo que no estamos aprendiendo y empapándonos de los conocimientos que deberíamos, ya que al no haber contacto personal, enfría muchísimo las clases y el ambiente de aprendizaje.

\section{¿Cree que está teniendo algún impacto en términos de igualdad o desigualdad para el alumnado? y en caso afirmativo, ¿̇en qué sentido?}

Sí, hay un par de casos en mi clase que no cuentan con ordenador o conexión a internet, y están teniendo muchísimos problemas, a la hora de contactar con los profesores, y viceversa. Nosotros cada vez que llega algún mensaje nuevo, lo mandamos por el grupo de WhatsApp de la clase, para todo aquel despistado o para aquellos que cuenten con este tipo de dificultades.

Balance de esta experiencia de confinamiento y de teletrabajo educativo: Principales debilidades y dificultades, situaciones de estrés, de conflicto con las hijas/ os, con la pareja, con las personas dependientes.

La convivencia nunca pudo ser perfecta, y a veces el estrés nos saca un poco de nuestras casillas, pero vamos como una vida normal de padres y una hija adolescente con un notable genio. [Risas].

Mis padres muy bien, mucho amor y Netflix nos ha unido mucho. [Risas]. 


\section{¿Algún aspecto positivo? ¿̇alguna contribución? ¿algo que se extraiga como una ven- taja en medio de esta situación compleja? ¿Alguna reflexión en términos de crecimien- to personal?}

La unión familiar que estamos forjando. Antes éramos más independientes, cada uno llevaba su rutina y sus quehaceres. Esta situación nos ha unido mucho, y hacemos actividades juntos, desde cocinar, sesiones de cine, videos graciosos, ejercicio... Lo que aún no he conseguido es jugar a un juego de mesa, y mira que lo he intentado, pero poco a poco, aún nos queda tiempo en esta situación.

\section{Y en términos emocionales, afectivos y personales, ¿̇cómo se está viviendo? ¿Cómo se está gestionando?}

Al principio yo estaba más triste, y lo veía todo muy negro. A día de hoy, ya me he acostumbrado y no se está tan mal. Si bien es cierto que a veces tanto a mí como a ellos, nos entran pequeños bajones, ya que echamos de menos a familiares, amigos, o actividades que teníamos ya integradas en nuestra rutina. Por suerte, nos ha tocado vivir esta situación en el siglo xxi y contamos con medios, para poder hablar con ellos o verlos a través de distintas plataformas.

\section{Aprendizaje para el futuro.}

Me he sentido muy privilegiada, ya que a pesar del gran cambio que ha supuesto esta situación, el ser humano cuenta con una gran capacidad de adaptación, pero sobre todo si cuentas con comodidades. He tenido la suerte de contar con una gran casa, con un patio para poder salir y despejarme; cuento con internet, música, y muchas actividades que poder realizar aquí dentro.

Como aprendizaje me llevo que debemos contar con la suficiente madurez e inteligencia para afrontar todo tipo de situaciones que nos presente la vida y no perder nunca la sonrisa.

\section{Valoración sobre las consecuencias y el impacto educativo y social de esta crisis a corto y medio plazo, una vez que se supere la situación.}

España ya contaba con una situación complicada debido a la última crisis, y ahora que estamos remontando, nos hemos vuelto a frenar, y las consecuencias económicas, sociales y educativas supondrán un gran impacto que nos costará superar.

\section{Alguna consideración o comentario final que consideres adecuado o quieras hacer.}

El confinamiento nos ha hecho reflexionar y darnos cuenta, de que pequeñas tonterías y detalles que teníamos en nuestra rutina diaria, son de las cosas que más echamos de menos. Apunto pequeños ejemplos: el hecho de cruzarnos con nuestros compañeros por los pasillos del instituto, las quedadas espontáneas, las risas en clase con los profesores... 


\section{Alumna, 17 años, $2^{\circ}$ Bachillerato, IES Padre Suárez (Granada). Se prepara para poder acceder al Grado de Ingeniería Física el próximo curso académico}

Indica, por favor, cuántos miembros estáis conviviendo en casa en este momento de confinamiento, edad de cada miembro, nivel educativo de cada miembro y a qué se dedica, con especial atención a si se está en casa o tiene un empleo que le obliga a salir en este momento.

4 miembros: Mi hermano: 13 años, estudia $2^{\circ}$ de ESO. Mi madre: 40 años, visitadora médica (no tiene que salir de casa por trabajo), nivel académico universitario. Mi padre: 42 años, militar (no tiene que salir de casa de momento) y nivel académico universitario.

Explica brevemente cómo se distribuyen las labores del hogar entre sus miembros durante el confinamiento: tareas que se han realizado en el hogar durante la última semana y duración (aproximada) de cada tarea, así como miembro del hogar que la ha realizado. Señala también si ha cambiado esa distribución de tareas entre los miembros del hogar en relación a antes del confinamiento.

Pues todos los días nos vamos turnando para que todos hagamos las mismas tareas como tirar la basura o fregar las platos, mi padre es el único que sale de la casa para hacer la compra, y un día a la semana limpiamos la casa completa entre todos (2-3 horas).

Con respecto a la realización del trabajo escolar (tus deberes) durante el confinamiento, te pedimos, por favor, que respondas a las siguientes preguntas:

De qué medios tecnológicos dispones en casa (un ordenador, varios ordenadores, una tablet, un móvil inteligente, ninguno de éstos) para hacer el seguimiento virtual de tu deberes.

Tenemos varios ordenadores, tablets y móviles para que tanto mi hermano como yo podamos realizar las tareas.

¿Cómo es la conexión a internet que tenéis en tu casa (Tipo de conexión-4G, Fibra, Rural...-, Velocidad)?

Fibra.

Qué se está haciendo desde tu centro educativo, por qué vía te llegan los deberes, cómo es la interacción con tu tutor/a y con el resto del profesorado, cómo es la interacción con tu padre y con tu madre a la hora de hacer los deberes, si necesitas su ayuda ¿̇pueden ayudarte con los conocimientos que tienen?, cómo se corrigen tus ejercicios, cómo se está planteando la evaluación del $2^{\circ}$ trimestre.

Los profesores se ponen en contacto con nosotros a través del correo electrónico o por diversas plataformas como classroom o edmodo. Mandan las tareas a través de esas páginas y ponen fecha límite para realizarlas además de estar a nuestra disposición por si tenemos alguna duda.

La evaluación del $2^{\circ}$ trimestre se realizará con las notas que hemos tenido a principios de este trimestre y con los trabajos que mandan. Además algunos profesores ponen exámenes que debemos realizar en un tiempo determinado para así contar con más notas con las que calificarnos, pero esto es posible solo 
en algunas asignaturas, mientras que en otras, al no poder hacer los exámenes finales, es posible que nos afecte negativamente a la media del trimestre.

\section{Qué horario ocupan tus estudios y la realización de tus deberes a lo largo del día, qué tipo de actividades realizas, cómo es esa rutina diaria}

Los profesores mandan un calendario semanal con todas las tareas que hay que realizar y tú puedes organizarte como quieras.

Yo me pongo un rato por la mañana y otro por la tarde, procurando llevar siempre las tareas al día, además de estudiar para los exámenes que tenemos al volver.

Además de estudiar hago otras actividades como ejercicio, lectura o ver alguna serie.

\section{Indica si crees que esta forma de seguir el curso está teniendo algún impacto en tu} aprendizaje y en qué sentido

Aunque los profesores están intentando dar y explicar conceptos para que el curso no se paralice hay asignaturas más complejas (en mi caso física) que no pueden explicarse a través de Internet o con algunos apuntes que pasen los profesores para intentar que lo entendamos mejor.

En mi caso, no estoy teniendo mucho problema en prepararme los contenidos, los entiendo rápidamente y puedo entenderlos, pero algunos de mis compañeros sí que tienen problemas para entender algunos conceptos y les cuesta más.

Aunque los profesores intentan ayudarnos en todo lo que pueden, el no estar en clase nos perjudica porque allí a través de exámenes y pruebas nos preparaban más para lo que además nos viene a los alumnos de $2^{\circ}$ Bachillerato, la selectividad. En casa podemos realizar nosotros las pruebas de forma independiente, pero no es lo mismo hacerlo solo y no entender algo a estar realizándolo en clase y poder consultar al profesor directamente.

\section{Señala las dificultades que encuentras a la hora de hacer realizar los deberes de esta} manera.

En el mejor de los casos los profesores te envían un vídeo explicando la materia pero en otras asignaturas se limitan a enviarte unos apuntes que tienes que entender con sus actividades correspondientes y si tienes alguna duda preguntas al profesor que intentará responder lo antes posible.

\section{Cuáles son las principales conclusiones que extraes de esta experiencia educativa.}

Aunque estemos en nuestra casa y tengamos tiempo para estudiar el no saber cuándo vamos a volver hace que nos relajemos y desviemos de los estudios. Al no tener ninguna prueba cercana para calificarnos no vemos la necesidad de centrarnos tanto en los estudios como cuando íbamos a clase y preferimos hacer otras cosas antes que sentarse y avanzar en contenidos.

\section{Señala si crees que está teniendo algún impacto en términos de igualdad o desigual- dad para el alumnado y, en caso afirmativo, en qué sentido}

Sí creo que haya desigualdad, no a todo el mundo le resulta fácil avanzar por su cuenta en materia y entender el mismo los contenidos, además de que no todo el mundo tiene más de un ordenador o una red de Internet que sea rápida por lo que si hay varios miembros de la familia que deben usar el ordenador le resultará mas difícil hacer sus tareas en los plazos que ponen. 
Ahora te pedimos que hagas un breve balance de esta experiencia de confinamiento y de teletrabajo educativo con relación a las siguientes cuestiones:

Principales debilidades y dificultades, situaciones de estrés, de conflicto con tu madre, tu padre, tu hermano...

Al estar encerrado tanto tiempo conviviendo con cuatro personas hay momentos en que tenemos nuestras diferencias, aunque la mayor parte del tiempo cada uno está haciendo su trabajo, la mayoría de las veces en habitaciones distintas.

Aspectos positivos, algo que puedas extraer como una ventaja en medio de esta situación compleja, alguna reflexión en términos de crecimiento personal

Lo único que puedo sacarle de bueno a este tiempo de confinamiento ha sido la posibilidad de hacer otras actividades que de haber estado en días normales de clase no hubiera podido hacer.

Por otra parte preferiría poder salir y disfrutar de lo que nos quedaba de curso a mis compañeros y a mí ya que era el último curso que íbamos a estar todos juntos y queríamos aprovecharlo al máximo.

\section{Y en términos emocionales, afectivos y personales, ¿̇cómo lo estás viviendo? ¿̇cómo lo estás gestionando?}

En términos emocionales intento no pensar en el tiempo que queda de confinamiento sino que pienso en todo lo que haré cuando salga. Intento concentrarme en los estudios y en realizar otras actividades para que pase el tiempo más rápido.

\section{Qué aprendizaje extraes de esta experiencia de cara al futuro}

He aprendido a ser más autodidacta y a no depender tanto de los profesores para prepararme las asignaturas sino a buscar yo misma todas las dudas que tenga y solucionarlas por mi cuenta.

Te pedimos también que valores las consecuencias y el impacto educativo y social de esta crisis a corto y medio plazo, una vez que se supere la situación

En el impacto educativo la media de todos o casi todos los alumnos se va a ver afectada en la mayoría de los casos a peor al no contar con tiempo para poder seguir evaluándonos y no contar con la posibilidad de subir nota en asignaturas.

¿Cómo estáis viviendo el examen de selectividad desde esta situación? ¿ Hay miedos? $\dot{¿} Q u e ́$ os dice el profesorado? ¿ ¿ómo te sientes tú? $\dot{\imath} Y$ tus compañeras y compañeros de clase?

Pues hay miedos ya que no sabemos exactamente como será el modelo, los profesores todavía no nos han hablado del nuevo examen de selectividad ni de como va a ser. Aunque dicen que puede ser más fácil el hecho de no saber qué hay que hacer siempre nos crea alguna inseguridad a mí y todos mis compañeros. 